\title{
GESTÃo PÚBLICA DE ENERGIA E REDUÇ̃̃o DA POBREZA: UMA ANÁLISE DO USO SUSTENTÁVEL DE FONTES ALTERNATIVAS NO NORDESTE DO PARÁ
}

\author{
PUBLIC ENERGY MANAGEMENT AND POVERTY REDUCTION: AN ANALYSIS \\ OF THE SUSTAINABLE USE OF ALTERNATIVE SOURCES IN NORTHEAST OF \\ PARÁ
}

\author{
Fabricio Quadros Borges \\ IFPA - Instituto Federal do Pará \\ Unama - Universidade da Amazônia \\ posdoctorborges@gmail.com \\ Luana Amaral \\ IFPA - Instituto Federal do Pará \\ Unama - Universidade da Amazônia \\ doctorborges@bol.com.br
}

Submissão: $18 / 11 / 2020$

Aprovação: 12/02/2021

\section{RESUMO}

O objetivo deste estudo é de analisar a contribuição de fontes alternativas, enquanto bases de geração de eletricidade, junto ao processo de redução da pobreza em duas localidades do Nordeste paraense entre 2018 e 2019. Nesta perspectiva, a investigação avaliou projetos de geração de eletricidade a partir das fontes solar e biomassa, de maneira a identificar possíveis impactos socioeconômicos nestas localidades, decorrentes do uso destas fontes. A metodologia baseou-se em 621 entrevistas na região pesquisada e se utilizou de indicadores de representação da qualidade de vida, elaborados por Calvert-Henderson. O estudo constatou que a implantação dos projetos contribuiu para a redução da pobreza nas comunidades pesquisadas e favoreceu, razoavelmente, ao processo de desenvolvimento sustentável nas comunidades analisadas. Constatou-se um aumento do acesso à renda, acompanhado de melhorias na qualidade de vida daquelas populações, apesar das interrupções registradas durante o fornecimento de eletricidade no período analisado.

Palavras-Chave: Desenvolvimento; sustentabilidade; geração de eletricidade; qualidade de vida.

\begin{abstract}
The objective of this study is to analyze the contribution of alternative sources, as electricity generation bases, along with the poverty reduction process in two locations in the Northeast of Pará between 2018 and 2019. In this perspective, the investigation evaluated electricity generation projects at from solar and biomass sources, in order to identify possible socioeconomic impacts in these locations, resulting from the use of these sources. The methodology was based on 621 interviews in the researched region and used indicators of
\end{abstract}


representation of quality of life, elaborated by Calvert-Henderson. The study found that the implementation of the projects contributed to the reduction of poverty in the surveyed communities and favored, reasonably, the process of sustainable development in the analyzed communities. There was an increase in access to income, accompanied by improvements in the quality of life of those populations, despite the interruptions recorded during the supply of electricity in the analyzed period.

Keywords: Development; sustainability; generation of electricity; quality of life.

\section{Introdução}

A ampliação do acesso à energia, por meio de fontes adequadas e confiáveis, é essencial se as nações mais pobres do mundo quiserem escapar da armadilha da pobreza, conforme o Relatório dos Países menos desenvolvidos de 2017: acesso à energia Transformacional da Unctad (UNCTAD, 2017). A Unctad - Conferência das Nações Unidas sobre Comércio e Desenvolvimento atua conjuntamente aos governos de seus Estadosmembros e interage com outras organizações internacionais e comissões regionais, bem como com instituições governamentais, organizações não governamentais e do setor privado, vinculada também a associações comerciais, a institutos de pesquisa e universidades em várias partes do mundo.

A diversificação de fontes de geração de energia elétrica está inserida neste debate na medida em que cada fonte pode representar maiores ou menores possibilidades de acesso a eletricidade, de impacto ambiental, capacidade de geração de novos postos de trabalho e de redução da pobreza de maneira geral.

A pobreza é abordada pelo IBGE de maneira conjunta às condições de vida e desigualdade, de maneira a observar aspectos de inclusão ou exclusão social, indicadores de situação social, de vulnerabilidade ambiental e de qualidade de vida (IBGE, 2020).

Em virtude disso, organizações e pesquisadores buscam novas formas de obter energia de um modo mais limpo, a fim de que contribuam efetivamente para a melhoria da qualidade de vida da população, apresentando uma taxa mínima de poluição e, por fim, que sejam capazes de suprirem a demanda energética de uma determinada região. Tais características procuradas podem ser encontradas nas chamadas fontes renováveis, uma vez que são as mais utilizadas atualmente, fato propiciado por disporem de um potencial energético elevado e por possuírem recursos naturais que não se esgotam e são reabastecidos naturalmente.

O Brasil, país com território que contém um alto potencial energético, possui uma quantidade de recursos naturais extraordinária, e fundamenta sua produção de energia principalmente nas usinas hidrelétricas. Segundo Sayão (2015) mais de 180 grandes usinas hidrelétricas são responsáveis por aproximadamente $70 \%$ da produção nacional de energia elétrica. Este panorama se explica pela generosidade de recursos naturais disponíveis e principalmente na abundância hídrica presente na região amazônica; entretanto, o que se observa é uma variedade de projetos inacabados ou em processo de implantação e/ou operação não concluídos (SAYÃO, 2015).

No Estado do Pará, que concentra uma grande quantidade de recursos naturais disponíveis na Amazônia, e é possuidor de um elevado potencial energético, observa-se como principal fonte de geração a usina hidrelétrica de Tucuruí, localizada no município de mesmo nome. No entanto, o estado possui dificuldades em alinhar a sua produção energética ao desenvolvimento social e econômico de sua população.

No Nordeste do estado, algumas comunidades fazem uso de eletricidade oriunda de projetos de geração baseados em fontes renováveis. Esta condição se dá em virtude de serem 
comunidades isoladas, isto é, não vinculadas às linhas de transmissão que trazem energia da hidrelétrica de Tucuruí. Neste estudo, foram verificados dois projetos em operação nos municípios paraenses de Breves e Curralinho (Figura 1).

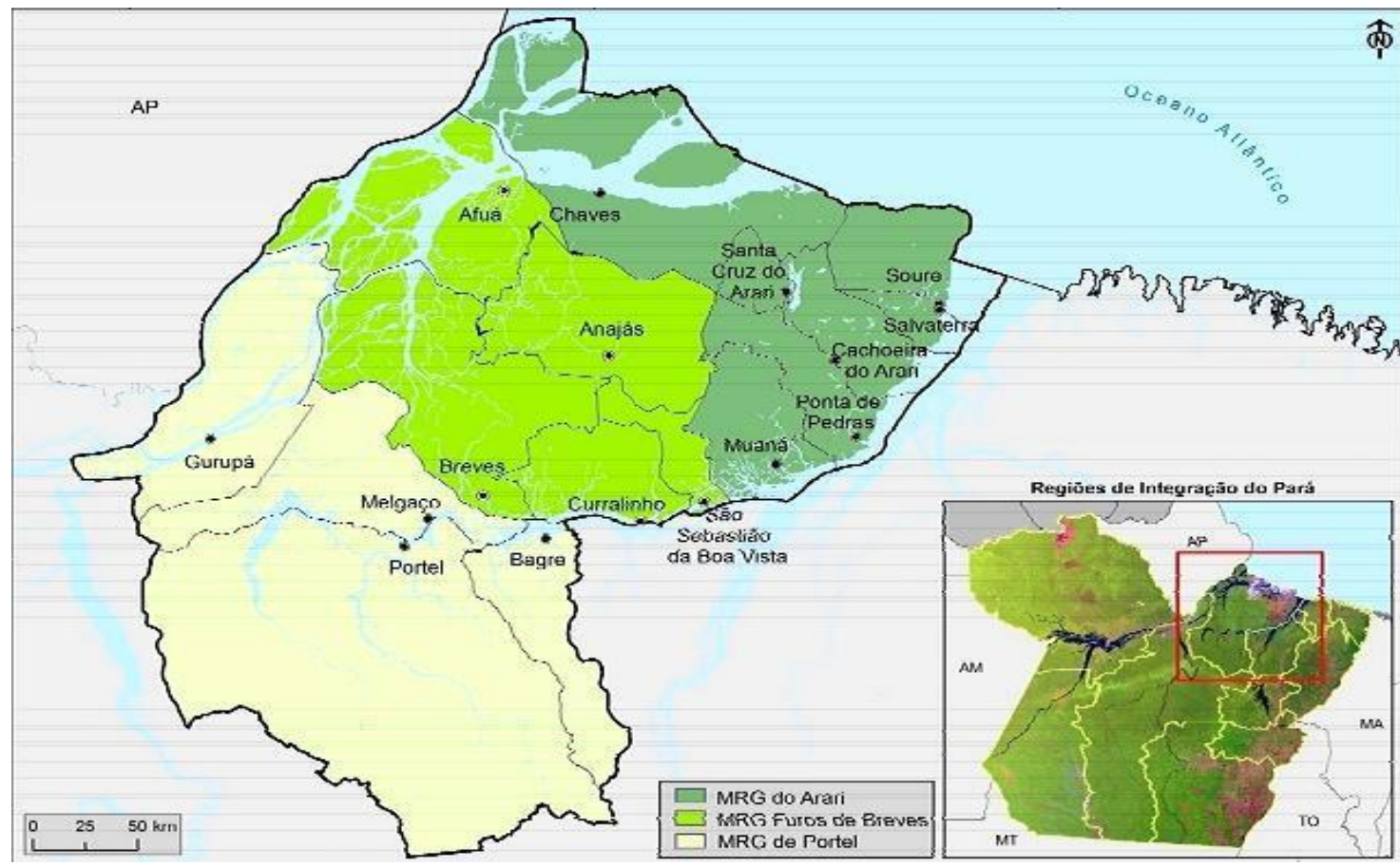

Figura 1: Mapa do Nordeste paraense.

Fonte: IBGE (2017).

É necessária a implantação de projetos desta natureza para que o uso de fontes alternativas, à geração hídrica, possa atenuar estas dificuldades, como as desigualdades sociais, a taxa de pobreza e os custos da eletricidade em decorrência das grandes distâncias entre as unidades de geração e muitas localidades paraenses.

Nesta perspectiva, observa-se desde os início dois anos de 2010 que no estado do Pará existe uma necessidade de um aprofundamento de estudos que evidenciem o uso de novas fontes de energia capazes de contribuir para o desenvolvimento sustentável, as quais estejam aptas a beneficiar efetivamente o setor elétrico local, atendendo a demanda elétrica solicitada e na melhoria da qualidade de vida das comunidades locais. Essas fontes são capazes de gerar uma relativa quantidade de energia com pouca ou até nenhuma poluição. Por isso, por meio de estudos junto a esta temática, verificou-se que o uso da energia solar e da energia oriunda da biomassa são recomendadas a algumas regiões paraenses na medida em que o potencial de radiação solar é de cerca de 120 calorias por centímetro e que a capacidade de geração de biomassa é de 309 toneladas por hectare em algumas mesorregiões (BORGES; ZOUAIN, 2010).

Assim, o estudo busca questionar: o uso das fontes solar e biomassa para a geração de eletricidade contribui sustentavelmente para a redução da pobreza nas comunidades do nordeste paraense?. O objetivo desta investigação foi o de analisar o panorama de contribuição das fontes solar e biomassa, enquanto projetos de geração de energia elétrica, como possibilidade contribuinte a redução da pobreza, de duas localidades do Nordeste paraense entre 2018 a 2019. Neste sentido, o estudo pretende verificar a operação de uso destas fontes alternativas para a geração de eletricidade nestas comunidades; assim como, 
identificar os impactos socioeconômicos, no ambiente da qualidade de vida, decorrentes do uso destas fontes para o desenvolvimento sustentável nestas localidades.

Esta investigação se justifica pelo fato de que a fonte hídrica, dominante no perfil de geração no Pará, causa impactos significativos na fauna e na flora local onde as usinas são implantadas, além de causarem impactos sociais negativos nas comunidades circundantes, contribuindo para a degradação do meio ambiente. A partir disso, este trabalho busca levantar subsídios para o uso das fontes solar e biomassa em outras regiões do estado do Pará na intenção de reduzir o uso da hidroeletricidade no estado e assim diminuir os efeitos causados pela mesma.

\section{Referencial Teórico}

O ambiente da gestão pública de energia é desenvolvido através de políticas públicas no setor elétrico, que geralmente pretendem demonstrar que os investimentos objetivam o crescimento econômico e a melhoria das condições de vida da população. A energia elétrica compreende o produto de um processo adequado de uso de propriedades físico-químicas e eletromagnéticas da matéria para propiciar o funcionamento de equipamentos fornecedores de usos finais pela sociedade (REIS et al, 2005). Estes usos são decorrentes de processo de geração de várias fontes e é justamente nesta perspectiva de abordagem teórica que se apresenta, a seguir, uma discussão a respeito do processo de uso de fontes alternativas de geração de eletricidade como contribuintes sustentável a redução da pobreza. Esta seção é composta dos tópicos: Pobreza e privação da vida; Desenvolvimento sustentável, qualidade de vida e o papel da energia elétrica; e Fontes alternativas de geração de energia elétrica;

\subsection{Pobreza e privação da vida}

A definição de pobreza é categorizada como juízo de valor quando se refere a uma interpretação subjetiva e abstrata do indivíduo, acerca do que deveria ser um nível suficiente de satisfação de necessidades, ou do que deveria ser um grau de privação normalmente suportável (CRESPO; GUROVITZ, 2002).

De acordo com Sen (2000), é importante compreender que a redução da pobreza de renda não pode ser o único propósito de políticas de combate à pobreza. Ainda conforme o autor, não é recomendável compreender a pobreza conforme uma perspectiva limitada da privação de renda e a partir daí justificar investimentos, com o argumento de que são bons meios para a redução da pobreza. A pobreza deve ser compreendida como a privação da vida que as pessoas realmente podem levar e das liberdades que elas realmente têm. A expansão das capacidades humanas enquadra-se justamente nesse ponto (SEN, 2000). Não se pode esquecer que o aumento das capacidades humanas tende a caminhar junto com a expansão das produtividades e do poder de auferir renda; um crescimento de capacidades auxilia ao enriquecimento da vida humana e a tornar as privações humanas mais raras e menos crônicas (SEN, 2000). Esta abordagem pode concernir a diversos elementos que vão além da carência econômica, tais como saúde, educação, habitação, participação política, igualdade entre os sexos etc. (SOARES, 2009; CODES, 2008). A importância deste conceito se apoia em indicadores utilizados na construção do índice de pobreza multidimensional e em algumas dimensões dos objetivos do desenvolvimento sustentável (SILVA; BRUNO; SILVA, 2020), daí a importância de tratar a pobreza pelo viés da sustentabilidade.

No Brasil, a pobreza é estudada pelo IBGE de modo conjunto as condições de vida e desigualdade, de forma a destacar a inclusão ou exclusão social, os indicadores de situação social, de vulnerabilidade ambiental e de qualidade de vida (IBGE, 2020). No tocante a categoria qualidade de vida, este estudo atribuirá maiores possibilidades de verificar o padrão socioeconômico das populações envolvidas na pesquisa. 


\subsection{Desenvolvimento sustentável, qualidade de vida e o papel da energia elétrica}

O conceito principal de desenvolvimento sustentável foi apresentado no Relatório de Brundtland ou "Nosso Futuro Comum" em 1897, quando afirma que o desenvolvimento sustentável é aquele desenvolvimento que atende as necessidades atuais, sem comprometer a habilidade das futuras gerações de atender suas próprias necessidades. Pode-se dizer que é um processo de mudança no qual a direção de investimentos, a orientação do desenvolvimento tecnológico e a mudança institucional estão em acordo para elevar os potenciais correntes e futuros capazes de reunir as necessidades e pretensões humanas (WCED,1991). Nesta perspectiva, o desenvolvimento sustentável só é possível ocorrer por meio de um equilíbrio entre os aspectos econômico, social e ambiental. A procura pelo desenvolvimento sustentável no longo prazo gera um interesse crescente por novas formas de energia mais limpas e renováveis, de modo que possibilite a satisfação das necessidades energéticas (BRAGA, 2008) e por possibilidades efetivas de contribuição a qualidade de vida das pessoas.

Qualidade de vida compreende uma percepção do indivíduo de sua posição na vida diante de um contexto cultural e sistema de valores, nos quais vive e em relação aos seus propósitos, expectativas, preocupações e situação ética, que deve, sobretudo, ser considerada a partir da percepção individual de cada um (WHOQOL, 1994; GILL; FEISNTEIN, 1994; SANTIN, 2002; PEREIRA; TEIXEIRA; SANTOS, 2012). Nesta discussão, destaca-se a contribuição didática de Nahas (2003), quando afirma ser a qualidade de vida uma condição humana resultante de dois conjuntos de parâmetros, os socioambientais e os individuais, modificáveis ou não, e que caracterizam as condições em que vive o ser humano. Ainda segundo o autor, esses conjuntos de parâmetros englobam diversos fatores que interferem de maneira determinante na qualidade de vida de um indivíduo ou de uma população.

Day e Jankey (1996) tratam as pesquisas sobre qualidade de vida de acordo com quatro abordagens gerais: econômica, psicológica, biomédica e geral ou holística. Dependendo da área de interesse, conforme destacam Pereira; Teixeira; Santos (2012), o conceito, muitas vezes, é adotado como sinônimo de saúde, felicidade e satisfação pessoal (MICHALOS, ZUMBO \& HUBLEY, 2000; SCHMIDT, POWER, BULLINGER \& NOSIKOV, 2005; RENWICK; BROWN, 1996). Calvert-Henderson (2000), usando indicadores de representação da qualidade de vida, definiu cinco dimensões de indicadores: renda, meio-ambiente, saúde, lazer e habitação; estes indicadores são mencionados e destacados por Alves (2011).

\subsection{Fontes alternativas de geração de energia elétrica}

As fontes alternativas de energia contribuem para o processo de desenvolvimento sustentável e estão diretamente relacionadas ao termo. Desde que o aquecimento global passou a ser um problema de âmbito mundial, nações vêm discutindo formas de diminuição das emissões de dióxido de carbono, e de outros gases que provocam o efeito estufa. Bem como abordado anteriormente, a ideia de desenvolvimento sustentável começou a ser discutida no início da década de 70 , onde negociações sobre questões relativas às mudanças climáticas, a redução de impactos no meio ambiente e combate à pobreza foram realizadas (BIRNFELD, 2014). O padrão dominante bastante presente na produção de energia é aquele proveniente de insumos não renováveis, motivo esse por apresentar um baixo custo de produção. Não obstante, diante da possibilidade de esgotamento desses recursos e, principalmente, diante da pressão de órgãos ambientais, faz-se necessário modificar a situação atual em prol de melhorias nos níveis de sustentabilidade (FREITAS, 2013).

Neste contexto, incentivou-se a utilização de fontes alternativas para a geração de eletricidade, considerando suas vantagens quanto ao menor impacto socioambiental. As fontes convencionais provocam impactos significativos capazes de afetar a sociedade próxima ao local, além de prejudicar a fauna e a flora nativa. No entanto, todas as fontes de energia 
devem ser utilizadas de maneira sustentável e econômica para que possam garantir sua utilização de forma contínua e segura (BORGES; ZOUAIN, 2010).

\subsubsection{Fonte Solar}

O uso de energia solar começou a ser discutido na década de 1960. No início, a ideia não se sustentou devido aos preços dos combustíveis e das exigências geradas por essa nova técnica, que na época era pouco conhecida. No entanto, a partir do início dessa discussão, surgiram diversos métodos e tecnologias para obter energia. Esta energia é descrita por Tiradentes (2007) como gratuita, renovável e não poluente. Devido à capacidade da incidência solar que o planeta recebe, algumas estimativas afirmam que se todo o potencial de energia solar em escala mundial fosse utilizado como fonte de geração de energia, seria possível gerar um percentual de energia duas mil vezes mais do que a produção total de todas as usinas nucleares, termoelétricas e hidrelétricas (BIRNFELD, 2014).

Existem duas formas de se obter energia elétrica a partir da fonte solar, que pode ocorrer pela: a) energia solar fotovoltaica, que é gerada por meio de painéis solares fotovoltaicos; e pela b) energia solar térmica que obtém energia por intermédio do armazenamento de calor obtido pela luz solar. A energia solar fotovoltaica foi utilizada primeiramente, obtendo destaque na alimentação de pequenos sistemas isolados, de projetospiloto e de eletrificação de equipamentos solitários (REIS, 2012), hoje, todavia, já é possível a ligação de tais sistemas às redes de distribuição. Esta energia consiste na conversão de irradiação solar em eletricidade através semicondutores capazes de transformar fótons de luz em eletricidade, por meio dos painéis fotovoltaicos.

O grande desafio de gerar energia elétrica por meio da fonte solar fotovoltaica é a relação custo-benefício que impede a utilização desta fonte em grande escala. A tecnologia e os equipamentos utilizados ainda são caros e de difícil acesso à grande parte da população. Os custos variam de acordo com a qualidade do recurso e do módulo solar utilizado, mas são normalmente mais altos do que o custo da geração de uma energia convencional (FABESP, 2007). .

\subsubsection{Fonte Biomassa}

A biomassa, do ponto de vista energético, é toda matéria orgânica (de origem animal ou vegetal) que pode ser utilizada na produção de energia (ANEEL, 2008). Essa matéria orgânica compreende a matéria vegetal gerada pela fotossíntese e seus diversos produtos e subprodutos derivados, tais como florestas, culturas e resíduos agrícolas, como também o de origem animal como dejetos de animais e a matéria orgânica encontrada nos rejeitos industriais e urbanos (BIRNFELD, 2014). No entanto, classifica-se como agrícola, florestal e rejeitos urbanos a biomassa utilizada para fins energéticos.

Cardoso (2012) observa que o uso da biomassa tem como vantagens o fato de ser uma fonte energética limpa e renovável, não contribuir com emissões que agravem o efeito estufa, ter seu aproveitamento direto por meio da combustão em fornos e ser capaz de gerar a redução de impactos socioambientais. $O$ interesse pela biomassa tem ganhado espaço no setor elétrico mundial devido ao seu enorme potencial energético, que segundo WWF (2012) normalmente é calculado a partir da disponibilidade de bagaço de cana-de-açúcar disponível no país. .

Conforme Freitas (2013), a biomassa é tipo de fonte que oferece uma mão de obra mais intensiva, representando cerca 52,6\% do total de empregos gerados nas diferentes fontes de energia renovável no mundo. Isso gera um saldo social positivo em termos de geração de empregos, principalmente em sistemas isolados e regiões em que as redes de distribuição de energia ainda não existem, atuando assim como colaborador para o desenvolvimento sustentável. 
De acordo com a União da Indústria de Cana-de-açúcar (UNICA), o potencial de geração de eletricidade que o bagaço da cana-de-açúcar pode ofertar é de 1,5 milhão de $\mathrm{kW}$ por ano, para alimentar o sistema elétrico brasileiro. Contudo, as fontes de biomassa são diversas sendo possível obter energia também por intermédio de lenha, carvão vegetal, babaçu, óleos vegetais, resíduos vegetais, sisal, biogás, casca de arroz (SOARES et al, 2006). Em consequência disso, percebe-se a copiosa quantidade de insumos que a biomassa possui para geração de energia elétrica.

Basicamente existem três formas de transformação da biomassa em um produto intermediário que é usado para a geração de eletricidade destacado por Cardoso (2012), que são os processos termoquímicos, bioquímicos e físico-químicos, no qual é necessário analisar viabilidade técnica e econômica de cada tipo de biomassa e da tecnologia a ser empregada para a otimização dos resultados. Apesar de existirem diferentes tecnologias de processamento e transformação em energia, todos esses processos, atualmente utilizados no mundo, possuem dois problemas cruciais: o custo da biomassa e a eficiência energética de sua cadeia produtiva (CORTEZ, 2008). Fato também corroborado por Cardoso, (2012) ao afirmar que outros problemas que o uso da biomassa oferece é a dificuldade no estoque e armazenamento da biomassa sólida, a adequada localização da fonte, a maior possibilidade de geração de material particulado e o poder calorífico que é reduzido.

\section{Metodologia}

Esta investigação, conforme a taxionomia de Castilho (2014) classifica-se como de natureza qualitativa, na medida em que procura compreender determinados fenômenos comportamentais através de coleta de dados narrativos; exploratória, no momento em que realiza um levantamento bibliográfico para a obtenção de dados suficientes capazes de gerar informações sobre o uso de fontes alternativas; descritiva, na medida em que analisa e observa as variáveis da contribuição nos padrões de qualidade de vida das comunidades estudadas a partir do uso de fontes alternativas. O estudo também classifica-se como bibliográfico e documental uma vez que realiza um levantamento de matérias de diversas fontes e na medida em que aborda dados secundários obtidos a partir de um projeto realizado por um instituto de desenvolvimento e meio ambiente. Esta metodologia está dividida em duas partes: Local de estudo e Técnicas de pesquisa.

\subsection{Local de Estudo}

O estudo foi realizado nas comunidades A e B localizadas na Ilha do Marajó, região Nordeste do Estado do Pará, situado na foz do rio Amazonas, logo ao sul da linha do equador que ocupa uma área de $48.000 \mathrm{~km}^{2}$ (IBGE, 2020). As comunidades estudadas situam-se no Nordeste paraense (Tabela 1). A comunidade A localiza-se no município de Curralinho, que possui uma população estimada em mais de 33.893 hab. A comunidade B localiza-se no município de Breves, que possui uma população estimada de 101.891 hab. (IBGE, 2020).

\section{Tabela 1: Projetos de geração de eletricidade a partir de fontes} alternativas no Nordeste do Pará.

\begin{tabular}{cccccc}
\hline Local & Comunidade & Fonte & $\begin{array}{c}\text { Capacidade } \\
\text { instalada de } \\
\text { geração }(\mathbf{K W})\end{array}$ & $\begin{array}{c}\text { Demanda } \\
\text { atendida } \\
\text { (n⿳⺈. residências) }\end{array}$ & $\begin{array}{c}\mathbf{N}^{\mathbf{0}} \text { de } \\
\text { entrevistas }\end{array}$ \\
\hline $\begin{array}{c}\text { Breves-Pa } \\
\text { Curralinho-Pa }\end{array}$ & A & Biomassa & 200 & 90 & 206 \\
\hline
\end{tabular}

Fonte: Elaborado pelos autores (2020).

A escolha das duas comunidades para a pesquisa foi realizada devido ao fato de as mesmas sediarem projetos de geração de eletricidade a partir de fontes alternativas utilizando recursos próprios obtidos no local; assim como por utilizarem respectivamente as duas fontes 
de geração recomendadas ao estado do Pará (BORGES; ZOUAIN, 2010). Os projetos são financiados pelo Programa de Incentivo às Fontes Alternativas de Energia Elétrica (PROINFA) do governo federal. A comunidade A sedia um projeto que objetiva conhecer o potencial de biomassa da região, para a implantação do projeto no município de Breves. Enquanto que a comunidade B, no município de Curralinho, sedia um projeto que tem o objetivo de analisar a potencialidade da energia solar na região. O sistema fotovoltaico da comunidade atende em torno de 300 famílias, cada uma com aproximadamente 4 membros. $\mathrm{O}$ sistema é fornecedor exclusivo de energia para a comunidade. Apenas em casos de emergência faz-se o uso de um gerador movido a diesel.

\subsection{Técnicas de Pesquisa}

As técnicas de pesquisa estão divididas em três partes: coleta de dados, tratamento de dados e análise de dados.

\subsubsection{Coleta de Dados}

A coleta de dados ocorreu em duas etapas. Na primeira etapa, foi realizada uma verificação em diversos artigos, periódicos, revistas e sites a fim de melhor compreender as categorias fontes alternativas de eletricidade e desenvolvimento sustentável. A segunda etapa constituiu-se em uma pesquisa documental, a qual reuniu dados secundários advindos de um banco de dados pertencente a uma fundação para o desenvolvimento regional que abordou o uso das fontes alternativas de geração de eletricidade no Pará.

O banco de dados que será utilizado baseou-se em uma pesquisa de campo que utilizou entrevistas abertas junto a membros de duas comunidades que se utilizaram destas fontes alternativas, em um total de 621 entrevistados. O recorte temporal do estudo ocorreu entre março de 2018 e novembro de 2019. Os dados referem-se a tipos de geração de eletricidade, moradia, educação, condições de trabalho, opções de lazer e outros parâmetros que ajudam a caracterizar a realidade das comunidades estudadas.

\subsubsection{Tratamento de Dados}

A pesquisa realizou esta etapa reunindo dados secundários capazes de fornecer informações sobre as possíveis contribuições no desenvolvimento sustentável nas comunidades estudadas a partir do uso de fontes solar e biomassa como fornecedora de energia elétrica. $\mathrm{O}$ estudo optou pela formulação de tabelas simples e gráficos de barras que facilitassem a compreensão e a leitura adequada das características que as comunidades apresentaram após a implantação dos projetos de energia.

Esta etapa possibilitou uma importante sistematização dos dados extraídos do banco de dados de maneira a possibilitar operacionalmente a observação das relações entre a geração de eletricidade a partir de fontes alternativas e os parâmetros socioeconômicos das duas áreas analisadas.

\subsubsection{Análise de Dados}

$\mathrm{Na}$ última etapa, a análise de dados desenvolveu um método para avaliar a contribuição do uso das fontes alternativas para o desenvolvimento sustentável das comunidades analisadas, utilizando indicadores de representação da qualidade de vida elaborado por Calvert-Henderson (2000), a fim de verificar, de modo mais qualitativo, as contribuições exercidas pelo uso das fontes solar e biomassa (Tabela 2). Este método possibilitou a relação de dados pertinentes a inserção das fontes de geração de eletricidade nas comunidades e dados pertinentes às possíveis modificações de perfil socioeconômico nestas mesmas comunidades. A escolha desses indicadores de Calvert-Henderson ocorreu por sua clareza e abrangência na caracterização do padrão de vida de determinada população. 
Tabela 2: Indicadores de Calvert-Henderson e suas contribuições para o desenvolvimento sustentável.

\begin{tabular}{cl}
\hline INDICADORES & \multicolumn{1}{c}{ CONTRIBUIÇÃO } \\
\hline Renda & Famílias com acesso a renda devido à implantação dos sistemas. \\
Meio-Ambiente & $\begin{array}{l}\text { Percepção do uso de insumos renováveis e pouca poluição gerada. } \\
\text { Saúde }\end{array}$ \\
Melhoria nas condições de assistência médica por intermédio da constância do \\
fornecimento de energia. \\
Habitação & Acesso à energia elétrica por iluminação pública em espaços comuns a todos. \\
\hline
\end{tabular}

Fonte: Adaptada pelos autores a partir de Calvert-Henderson (2000).

A medida de qualidade de vida está relacionada ao desenvolvimento de um local, a partir do momento que utiliza indicadores socioeconômicos (Emprego, Meio-Ambiente, Saúde, Lazer e Habitação) para realizar tal medida, e também pela possibilidade de relacionar o uso dessas fontes à melhoria na qualidade de vida das comunidades, ocasionando na formação do desenvolvimento sustentável local.

\section{Resultados e Discussão}

Esta seção pretende proporcionar uma compreensão sistemática da contribuição das fontes solar e biomassa, enquanto bases de geração de eletricidade, junto ao processo de desenvolvimento sustentável de duas localidades do nordeste paraense entre 2018 e 2019 . O processo de desenvolvimento sustentável tomou como referência de avaliação neste estudo, os indicadores socioambientais elaborados por Calvert-Henderson (2000) que são capazes de mostrar a real situação sobre a qualidade de vida de cada comunidade.

Estes indicadores foram utilizados como base para obter as seguintes informações obtidas como: famílias com acesso a renda devido à implantação dos sistemas; percepção do uso de insumos renováveis após a implantação dos projetos; grau de satisfação dos moradores quanto a melhoria nas condições de assistência médica por intermédio da constância do fornecimento de energia; acesso à energia elétrica por iluminação pública em espaços comuns a todos; e número de aparelhos elétricos por residência.

A comunidade A utiliza como principal fonte energética a biomassa. Foi implantado um sistema a vapor de $200 \mathrm{~kW}$ que obtém resíduos de serrarias próximas a comunidade. Como bem destaca Padilha et al. (2005), o Pará possui uma variedade imensurável de espécies florestais madeireiras, capaz de tornar-se uma grande fonte de suprimentos ao setor madeireiro. O funcionamento do sistema é realizado pela própria comunidade através de uma associação dos moradores que elege um membro para administrar os recursos utilizados obtidos pelo sistema. A comunidade B, que possui como insumo a energia solar, dispõe de um sistema fotovoltaico com capacidade para atender em torno de 300 famílias em uma comunidade de aproximadamente 1.100 habitantes. Os painéis foram instalados por técnicos responsáveis ao longo de aproximadamente um ano e meio, sem o auxílio da comunidade. A seguir, apresentam-se os resultados e discussões a partir de cada indicador de CalvertHenderson (2000): renda, meio ambiente, saúde, lazer e habitação.

\subsection{Indicador Renda}

A análise do indicador renda verificou a quantidade de famílias com acesso a renda devido à implantação do sistema. É possível constatar que as comunidades pesquisadas obtiveram resultados diferentes após a implantação das fontes alternativas de geração de eletricidade. Apesar de ambas apresentarem melhorias nas condições de trabalho a partir da utilização de eletricidade por meio das novas fontes, o processo produtivo de cada 
comunidade foi explorado de maneiras distintas, o que resultou em um contraste significativo nas atividades geradoras de renda.

A comunidade A atingiu um percentual de $92 \%$ de famílias que afirmam ter acesso a renda após a implantação do sistema (Figura 2). Isso deve-se ao fato de que a comunidade sedia uma fábrica de gelo que pertence à própria cooperativa local, gerando trabalho e consequentemente renda para os funcionários que são os próprios moradores da comunidade, além de ter o sistema ligado ao próprio consumo das famílias. A comunidade possui uma localização que permite um fluxo de barcos pesqueiros considerável na região, proporcionando outras atividades capazes de gerar renda para a comunidade. Através deste percentual é possivel dizer que o sistema é capaz de suprir toda a demanda de energia solicitada pela comunidade, atendendo tanto o consumo das famílias como o consumo de atividades comerciais, como o caso da fabrica de gelo. Outro ponto positivo para o alcance de um percentual quase total de famílias com acesso a renda foi o fato propiciado pela comunidade, que soube gerenciar o uso da energia, proporcionando fontes de renda para a própria comunidade, estimulando o comércio local.

Na comunidade B, que utiliza os painéis fotovoltaicos para geração de energia, observou-se um percentual de apenas $37 \%$ das familias que obtiveram acesso à renda após a implantação do sistema, apresentando um resultado pouco satisfatório em comparação a comunidade anterior. Isso ocorreu em virtude de que, para algumas famílias, esta foi a primeira vez em que houve energia elétrica em suas casas, ou seja, como novidade, o uso de energia foi mais utilizado como forma de consumo residencial, através de aparelhos eletrodomésticos que oferecem conforto às famílias. . A significativa discrepância entre os percentuais de famílias que afirmam ter acesso a renda após a implantação do sistema está relacionado à maneira que cada comunidade utiliza o consumo de energia elétrica nas atividades geradoras de renda, dispondo cada uma de suas particularidades.

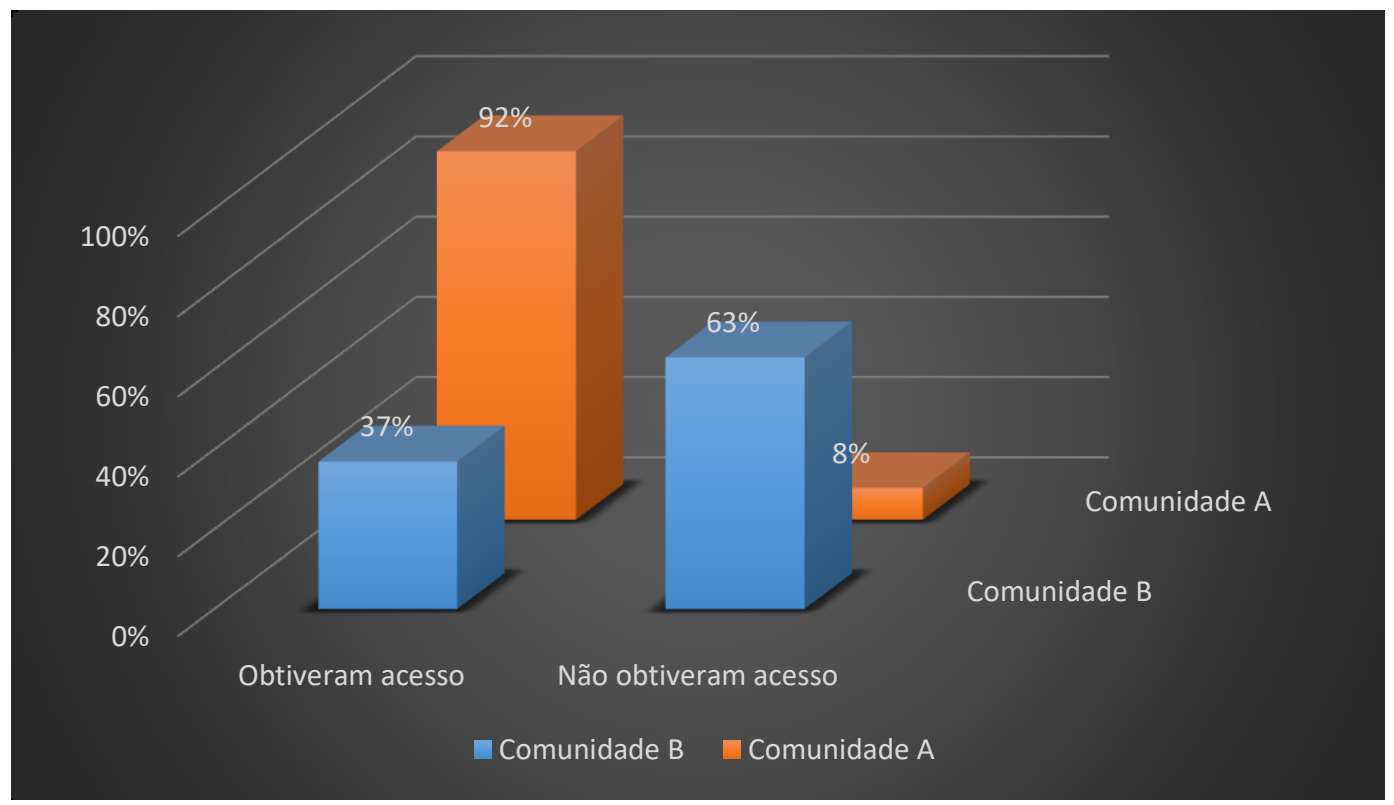

Figura 2: Famílias com acesso a renda devido à implantação dos sistemas.

Fonte: Elaborado pelos autores (2020).

Ainda quanto ao acesso à renda por parte das famílias, verificou-se que a maioria dos entrevistados afirmou que os sistemas implantados em suas respectivas comunidades beneficiou-os de modo direto e indireto com relação ao acesso a alguma forma de renda, seja por produção de alimentos que necessitam de refrigeração ou a conservação de pescados para 
posterior comercialização. Todo este contexto caracteriza uma melhoria nas condições de trabalho proporcionada pela implantação dos sistemas de geração de energia elétrica a partir de fontes alternativas. Destaca-se que estas condições de trabalho compreendem outro fator de composição dos parâmetros socioambientais de Nahas (2003).

\subsection{Indicador Meio Ambiente}

$\mathrm{O}$ indicador meio ambiente destacou, neste estudo, o percentual de percepção da comunidade no uso de insumos renováveis após a implantação dos projetos. A principal fonte para a geração de energia em ambas as comunidades é através de insumos renováveis dispostos na própria região, capazes de subsidiar a quantidade necessária para o consumo de cada comunidade. No entanto, existem especificidades que determinam o quanto cada insumo é utilizado (Figura 3).

A investigação constatou que a comunidade A obteve um alto aproveitamento (97\%) do uso de insumos renováveis após a implantação do sistema. Isso ocorreu em virtude de o sistema à vapor utilizar como insumo os resíduos provenientes de serrarias próximas ao local, capazes de gerar um reaproveitamento deste insumo. Naturalemte, quanto mais os resíduos são utilizados, maior é a oferta de eletricidade para a localidade. A utilização de insumos renováveis gera uma cadeia produtiva de energia sustentável, empregando resíduos que anteriormente não possuíam um destino final adequado, contribuindo ao desenvolvimento sustentável na comunidade. Este percentual foi alcançado devido ao apoio da comunidade, visto que o sistema utiliza os resíduos de serrarias próximas; por isso a percepção da comunidade quanto ao uso de insumos renováveis após a implantação do projeto foi elevada. Este panorama associado às formas de energias mais limpas e renováveis, de maneira a possibilitar a satisfação das necessidades energéticas, verificado na comunidade A, encontra vínculo com a ideia de desenvolvimento sustentável mencionada por Braga (2008).

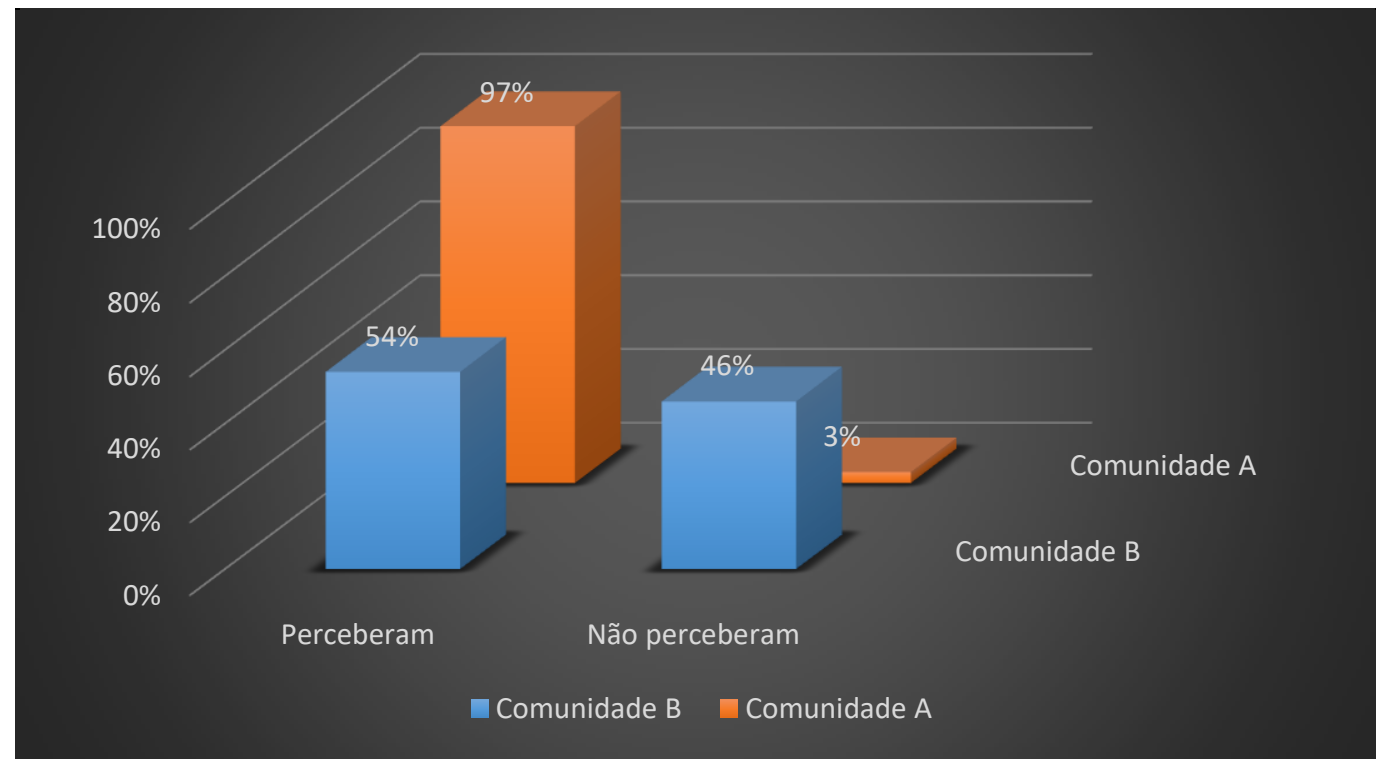

Figura 3: Percepção de uso de insumos renováveis após a implantação dos projetos. Fonte: Elaborado pelos autores (2020).

$\mathrm{Na}$ comunidade $\mathrm{B}$, apenas $54 \%$ do entrevistados perceberam o uso de insumos renováveis após a implantação do projeto. Essa percepção sobre a utilização da fonte solar como insumo para a geração de energia foi prejudicada devido ao sistema ser operado por técnicos especializados, que contribui em um distanciamento entre a utilização deste insumo e a percepção da comunidade. Outro ponto relevante, evidenciado através deste percentual, é que o insumo utilizado não é encontrado de modo palpável na comunidade, que utiliza um 
sistema de captação que não permite à comunidade uma integração no processo de produção de energia por meio da fonte solar. A percepção da comunidade sobre o uso de insumos renováveis, após a implantação dos projetos, é essencial às instituições promotoras para a continuidade dos projetos e esta percepção apresentou-se em intensidades diferentes entre as comunidades.

\subsection{Indicador Saúde}

O indicador saúde é um item fundamental para avaliar a qualidade de vida de uma determinada população. Dentre os conceitos determinantes para a saúde destacados por Minayao (2000), encontram-se os serviços de saúde. Estes serviços possuem relação direta ao fornecimento de eletricidade, considerando que a constância deste fornecimento possibilita melhorias na assistência médica oferecida nas comunidades. A comunidade B apresentou como melhor resultado, o percentual de $47 \%$ referente ao grau de satisfação dos moradores quanto a melhoria nas condições de assistência médica por intermédio da constância do fornecimento de energia. Este percentual é explicado devido ao fato de que o sistema solar não disponibiliza um fornecimento elétrico constante à comunidade, o que interfere diretamente na capacidade da comunidade em ofertar melhores condições de assistência médica a população local (Figura 4).

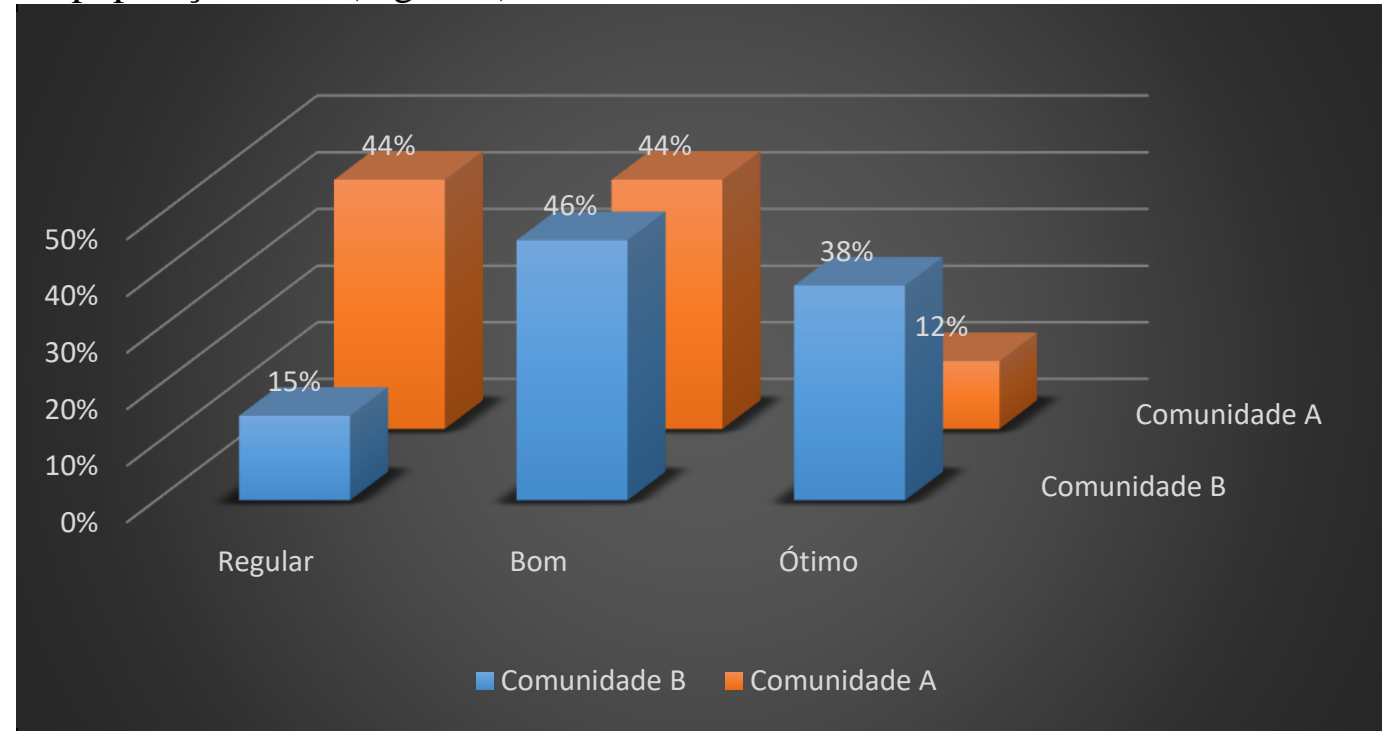

Figura 4: Grau de satisfação dos moradores, quanto a melhoria nas condições de assistência médica, por intermédio da constância do fornecimento de energia. Fonte: Elaborado pelos autores (2020).

Enquanto na comunidade A houve uma igualdade entre os percentuais classificados como BOM e REGULAR (44\%) para o grau de satisfação dos moradores quanto a melhoria nas condições de assistência médica, mostrando um grau satisfatório da comunidade. Vale ressaltar que este percentual ocorreu devido ao fornecimento de energia acontecer em períodos fixos e sofrer certas limitações sobre a intensidade da corrente ofertada para população, criando a possibilidade de uma organização para que durante os períodos de fornecimento de energia, aconteça simultaneamente aos serviços médicos ofertados para a população, ocasionando na melhoria das condições de assistência médica por intermédio da constância do fornecimento de energia, no entanto este processo encontra dificuldades devido o sistema sofrer limitações sobre a intensidade da corrente.

\subsection{Indicador Lazer}

O indicador lazer buscou uma relação entre o acesso à energia elétrica, por meio da iluminação pública em espaços comuns, e os índices de qualidade de vida. A iluminação 
pública constante em espaços comuns proporcionou à comunidade a oportunidade de realizar eventos que promovam um comércio entre os membros da própria comunidade e regiões próximas, gerando além de renda a interação da comunidade entre seus membros. A constância do acesso à energia elétrica por iluminação pública em espaços comuns se mostrou positiva em ambas as comunidades. Na comunidade A, registrou-se um percentual de $63 \%$ de fornecimento constante de energia elétrica (Figura 5). Os demais entrevistados mencionam interrupções oriundas basicamente da ausência de insumos para a alimentação do sistema a vapor. Em algumas residências existem geradores a diesel utilizados em momentos de emergência, seja por problemas de insumos da usina ou por incapacidade momentânea do sistema, o que pode ter causado a falsa impressão de um fornecimento constante para a maioria dos entrevistados.

$\mathrm{Na}$ comunidade B, o fornecimento constante foi mencionado por $69 \%$ dos entrevistados, devido ao sistema fotovoltaico localizar-se próximo as residências, facilitando o processo de fornecimento. É possível destacar por meio do percentual de ambas as comunidades que os projetos proporcionaram a elas uma alternativa importante de lazer na medida em que viabilizou a utilização de espaços comuns._.

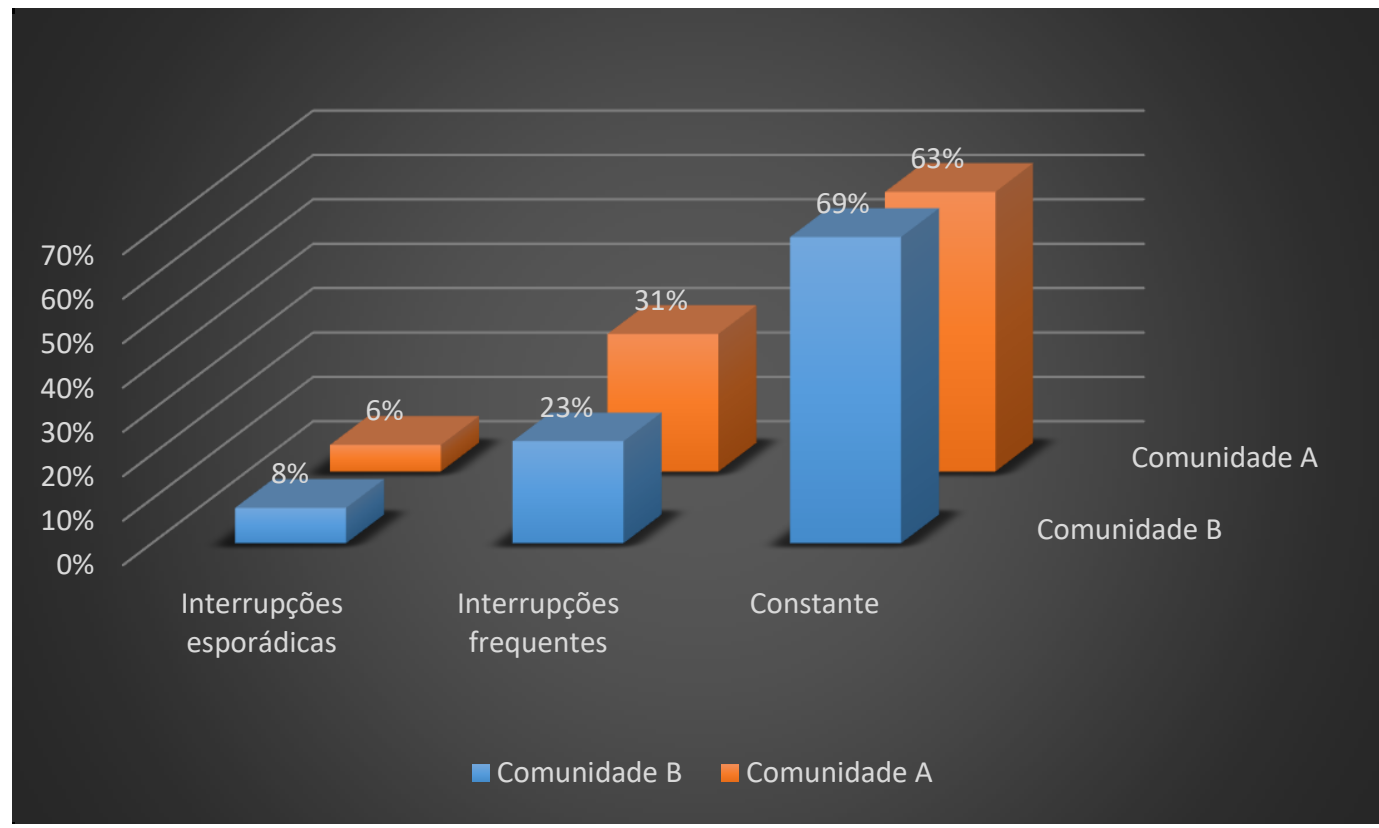

Figura 5: Acesso à energia elétrica por iluminação pública em espaços comuns a todos. Fonte: Elaborado pelos autores (2020).

A interação entre os membros da própria comunidade também merece registro. $\mathrm{O}$ usufruto destes espaços comuns, a partir da interação entre os membros da comunidade, no desfrute de melhores condições de vida, expande as capacidades humanas. Esta realidade está associada a ideia de Sen (2000), quando destaca que a pobreza deve ser compreendida como a privação da vida que as pessoas realmente podem levar e das liberdades que elas realmente têm, isto é, trata-se da expansão das capacidades humanas. $\mathrm{O}$ acesso a eletricidade e às possibilidades que este insumo proporciona contribui para a expansão das capacidades humanas.

\subsection{Indicador Habitação}

O indicador habitação está relacionado à quantidade de aparelhos elétricos por residência, visto que a utilização de tais aparelhos proporcionam uma melhoria na qualidade de vida das famílias. A comunidade $\mathrm{B}$ registrou um número maior de aparelhos elétricos por 
residência, onde $62 \%$ dos entrevistados possuem mais de três eletrodomésticos por residência (Figura 6). A capacidade elétrica da comunidade aumentou e tornou-se capaz de suportar um maior número de aparelhos domésticos. O número menor de interrupções no fornecimento ainda aumentou a vida útil dos aparelhos. Este percentual indicou também que a comunidade utiliza de modo mais intenso aparelhos eletrodomésticos dentro de suas residências, de maneira a proporcionar um maior bem estar. Nesta perspectiva, este bem estar, proporcionado pelo insumo energético, é associado a saúde, felicidade e satisfação poessoal, como bem destacam vários autores que estudam qualidade de vida (MICHALOS; ZUMBO; HUBLEY, 2000; SCHMIDT, POWER; BULLINGER; NOSIKOV, 2005; RENWICK; BROWN, 1996; TEIXEIRA; SANTOS, 2012).

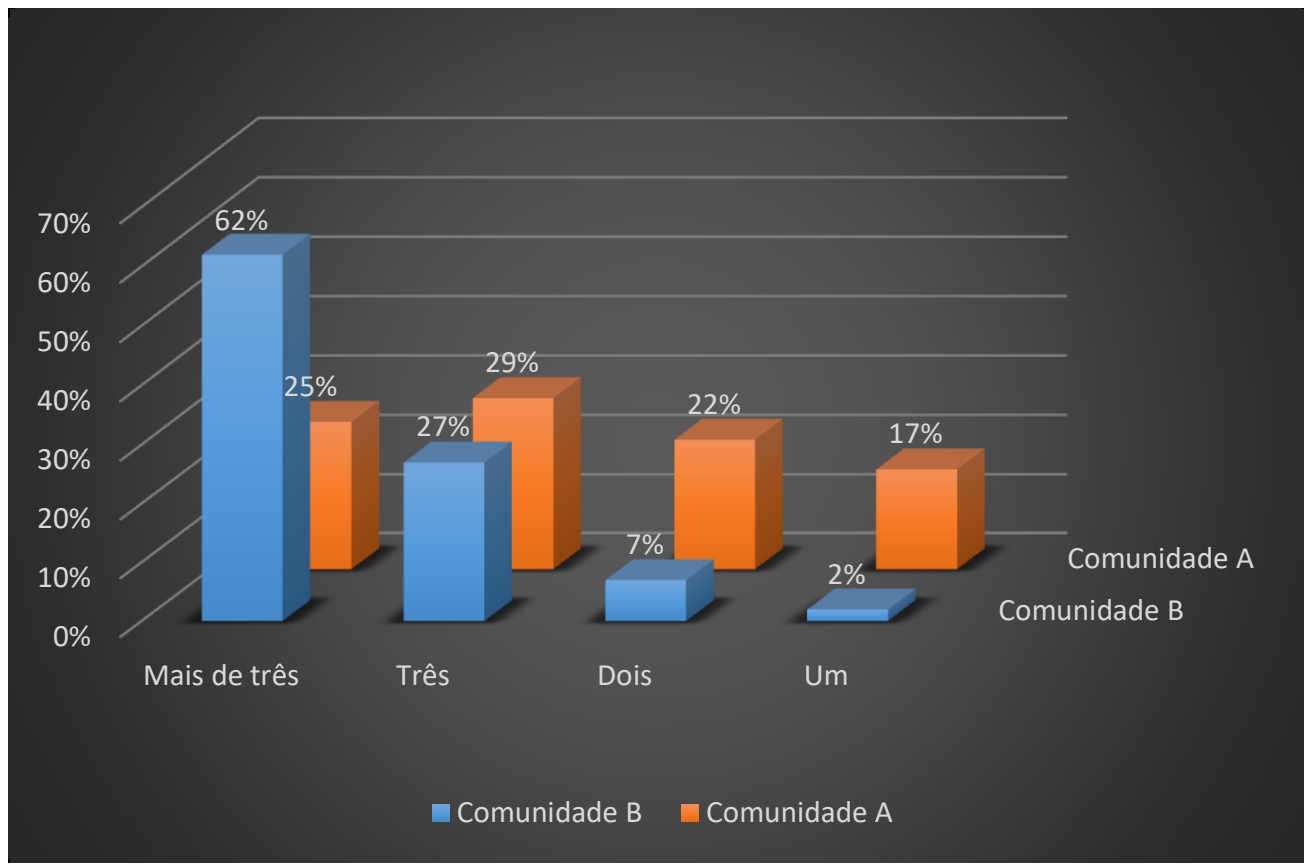

Figura 6: Número de aparelhos elétricos por residência.

Fonte: Elaborado pelos autores (2020).

De acordo com as entrevistas realizadas junto aos moradores locais, o acesso ao fornecimento de eletricidade e a diminuição de custos com óleo diesel fez com que as populações obtivessem um excedente de renda que foi destinada para a compra de equipamentos eletrônicos ou máquinas que dependem de energia elétrica para operarem. A comunidade A apresentou um número considerávelmente menor de aparelhos elétricos por residência, onde apenas $25 \%$ dos entrevistados possuem mais de três eletrodomésticos por residência. $\mathrm{O}$ fator indicativo para a decorrência deste percentual é que a comunidade está localizada em uma região afastada, que sugere uma maior dificuldade na obtenção de aparelhos domésticos, levando famílias a compartilharem o uso de aparelhos, sendo possível atender um número maior de famílias com uma quantidade menor de aparelhos.

$\mathrm{O}$ acesso aos aparelhos elétricos vem contrastar com dificuldades em localidades no Estado do Pará que muitas vezes possuem linhas de transmissão de eletricidade que passam centenas de quilômetros de terras habitadas, onde seus moradores não têm eletricidade em suas propriedades, cenário que não atende ao papel da eletricidade em um processo de desenvolvimento humano conforme Bittencourt (2011).

4.6. Análise dos indicadores entre as comunidades.

Os indicadores mensurados possibilitaram uma análise comparativa entre as comunidades com base nos dados obtidos durante o estudo, permitindo uma visão amplificada sobre o uso das fontes solar e biomassa, como contribuintes sustentáveis a redução da pobreza 
nas comunidades estudadas. Observou-se que cada comunidade reagiu de modo particular ao processo de eletrificação a partir das fontes alternativas. É importante destacar que a escolha do tipo de fonte utilizada em cada comunidade influencia nas modificações sofridas no modo de vida da população, visto que o sistema se diferencia possuindo vantagens e desvantagens distintas que mais se adequam as necessidades de cada comunidade.

É notório o caráter mais profissional exercido pela comunidade A, após a implantação do sistema, visto que as atividades geradoras de renda foram realizadas de maneira mais intensa naquela comunidade. Este caráter foi vericado por meio do próprio desempenho da população, que se empenhou em todo o processo instalação e operação do sistema. No entanto, a escolha do tipo de fonte utilizada como geração de energia influenciou consideravelmente no processo de funcionamento do sistema e a integração da comunidade junto a este processo, isto é, a escolha pela biomassa como insumo para a geração de eletricidade propiciou à comunidade um fluxo de atividades que permitiu a assistência por parte dos moradores durante as etapas, quanto ao funcionamento adequado do sistema. Neste sentido, o desempenho dos moradores foi fundamental para que o projeto fosse bem sucedido. Já na comunidade $\mathrm{B}$, não houve uma integração entre os moradores e o sistema implantado, isto porque o próprio sistema escolhido não permite que a comunidade acompanhem o sistema, durante o processo de geração de energia. A escolha pela energia solar, como fonte de geração para energia elétrica, influenciou diretamente este quadro, devido ao sistema operar sem a necessidade constante de mão-de-obra.

A comunidade B adotou um caráter de prevalência domiciliar, visto que a utilização da energia pelos moradores foi predominante em suas residências, por meio dos aparelhos elétricos utilizados. Por intermédio dos aparelhos elétricos é possível também exercer atividades geradoras de renda. O comportamento dos moradores diante do processo de eletrificação foi determinante para a definir o grau de eficiência da implantação do sistema na comunidade. Para muitos, este foi o primeiro contato com a energia elétrica, consequentemente, com aparelhos elétricos, o que torna os procedimentos adotados pela comunidade B, divergentes dos adotados pela comunidade vista anteriormente.

A escolha do tipo de fonte utilizada para cada comunidade foi refletida durante a percepção da comunidade quanto ao uso dos insumos após a implantação do sistema devido a cada comunidade apresentar percepções distintas sobre esta ocorrência. A comunidade A, que utilizou a Biomassa como fonte de geração de energia, apresentou uma percepção dos moradores mais significativa que a comunidade B. Este fato pode ser justificado pela diferença dos processos de geração de eletricidade em cada fonte. A biomassa possui um processo no qual depende de insumos de origem orgânica ou vegetal. Na comunidade foram utilizados resíduos de serraria produzidos por serrarias locais, ou seja, permite que a comunidade consiga mensurar a quantidade de insumos utilizados.

$\mathrm{Na}$ comunidade $\mathrm{B}$, que utiliza a fonte solar, a dinâmica é diferente. O processo de transformação da luz solar em energia eletrica é realizado pelos painéis fotovoltáicos que realizam todas as etapas de conversão. Para a comunidade, é difícil estimar a quantidade de luz solar utilizada para a transformação de energia, por isto a percepção dos moradores quanto ao uso dos insumos após a implantação do sistema é comprometida.

O indicador saúde apresentou características semelhantes entre as duas comunidades devido à constâcia no fornecimento de energia, que afeta diretamente as condições de assistência médica ofertadas. As duas comunidades apresentam interrupções durante o fornecimento de energia à comunidade, causadas por motivos específicos de cada sistema. A comunidade B não oferta um fornecimento constante para a comunidade, o que contribui para que a assistência médica apresente ressalvas destacadas pela comunidade. Por seu turno, a comunidade A não possui um intervalo fixo de fornecimento de energia e sofre de limitações na intensidade da corrente. 
As duas comunidades apresentaram resultados semelhantes quanto ao acesso de energia elétrica em espaços comuns a todos, o que permitiu a ambas ofertarem a sua população opções de lazer, promovendo uma interação entre os próprios membros da comunidade, além de promover atividades que estimulam o comércio local nestes espaços e o turismo da região

O carátér adotado por cada comunidade influênciou no número de aparelhos por residência (Habitação). A comunidade A obteve um número menor de aparelhos elétricos por residência devido ao caráter comercial adotado pela mesma, além de estar localizada em uma região mais afastada, o que dificulta a chegada de aparelhos à comunidade. $\mathrm{O}$ caráter mais domiciliar adotado pela comunidade $\mathrm{B}$ resultou em um número maior de aparelhos elétricos por residência, utilizado para o bem estar das famílias possuidoras de tais aparelhos.

$\mathrm{Na}$ Figura 7, observam-se os indicadores escolhidos para este estudo e o resultado de cada um deles sobre a implantação de uma fonte alternativa em comunidades isoladas no nordeste do estado paraense.

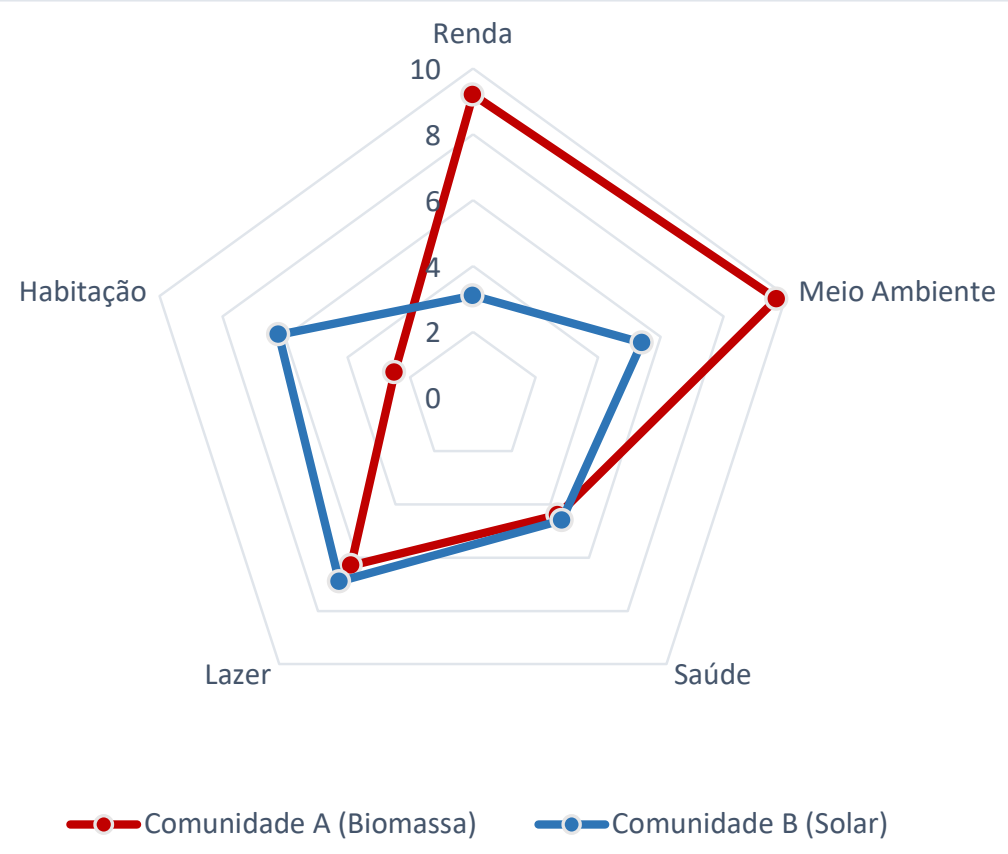

Figura 7: Análise dos indicadores de qualidade de vida de cada comunidade.

Fonte: Elaborado pelos autores (2020).

Os indicadores analisados contribuíram sustentavelmente a dimunuição da pobreza em ambas as comunidades, independente do tipo de escolha de fonte utilizada para a geração de eletricidade. As comunidades reagiram de modo distinto à implantação do sistema, o que ocasionou em resultados diferentes sobre as contribuições do uso de energia alternativa na comunidade. No entanto, para o desenvolvimento da comunidade, tal implantação foi de total importância. É possível observar os pontos altos de cada comunidade sobre os indicadores escolhidos, e por meio dos mesmos, nota-se a melhoria na qualidade de vida dos moradores proporcionando bem-estar, conforto, lazer, renda, saúde e satisfação através da implantação dos sistemas.

A dificuldade de manutenção nos projetos após a sua conclusão foi a principal dificuldade verificada. Alguns projetos anteriores foram abandonados pela dificuldade financeira de reposição de peças, o que não representava cerca de $8 \%$ do custo total de instalação. Outros projetos tiveram dificuldades de gerenciamento pela comunidade ou empresa que ficou incumbida da operação e dos reparos necessários. 
Em suma, os empreendimentos são considerados viáveis e podem ser autossustentáveis desde que estabelecidos critérios a serem seguidos, tanto para a população quanto para a gestão, como: capacidade instalada, pagamento pelo fornecimento ou complementação dos sistemas com atividades lucrativas que decorrem de sua funcionalidade, trazendo retorno para a administração e novos investimentos para os projetos. Isso leva a uma possibilidade de surgimento de novas ações baseadas em estratégias que possam ampliar o uso das fontes biomassa e solar para a geração de eletricidade no Pará. Outro ponto importante a ser destacado quanto a autossustentabilidade dos empreendimentos é a participação da população na instalação e na operação da produção de energia.

\section{Considerações Finais}

Esta investigação analisou o panorama de contribuição das fontes solar e biomassa, enquanto projetos de geração de energia elétrica, como possibilidade de redução da pobreza, de duas localidades do Nordeste paraense entre 2018 a 2019. As contribuições do uso das fontes escolhidas foram medidas através de indicadores de qualidade de vida, capazes de expor a real situação social, econômica e ambiental, nas comunidades pesquisadas.

O estudo constatou que a implantação dos projetos foi contributiva ao processo de desenvolvimento sustentável nas comunidades pesquisadas e alcançou os razoáveis valores econômico, social e ambiental. No entanto, cada projeto possui suas peculiaridades. O estudo identificou uma diminuição da pobreza nas comunidades a partir do acesso à renda que as mesmas obtiveram, e apesar das interrupções sofridas durante o fornecimento de energia elétrica, houve melhorias significativas e fundamentais na qualidade de vida da população, a partir do grau de satisfação dos moradores nas condições de assistência médica, do uso de aparelhos eletrodomésticos que se tornou possível através da implantação do sistema, da iluminação pública que proporcionou atividades tanto para âmbito comercial como para o lazer, e, por fim, a utilização de insumos renováveis que anteriormente não eram utilizados ou não possuíam um descarte final adequado. Essas contribuições que o uso de fontes solar e biomassa proporcionaram às comunidades analisadas no Pará favoreceram ao processo de desenvolvimento sustentável, por meio do atendimento da demanda elétrica e contribuindo para a melhoria da qualidade de vida da população.

Os empreendimentos são considerados viáveis e podem ser plenamente autossustentáveis, desde que seguidos os critérios tanto para a população quanto para a gestão, como capacidade instalada, pagamento pelo fornecimento ou complementação dos sistemas com atividades lucrativas que decorrem de sua funcionalidade, trazendo retorno para a administração e novos investimentos para os projetos. Isso leva a uma possibilidade de surgimento de novas ações baseadas em estratégias que possam ampliar o uso das fontes biomassa e solar. Registra-se ainda outro ponto relevante a ser mencionado na análise da autossustentabilidade dos empreendimentos, que é a participação da população na instalação e na operação da geração de eletricidade.

A investigação enfrentou limitações devido à impossibilidade de complementaridade de dados em virtude da grande distância destas comunidades. Os dados utilizados foram apenas os registrados no banco de dados que pertence a uma fundação de desenvolvimento regional. Neste sentido, as informações se tornaram limitadas sobre o processo de implantação e operação dos projetos escolhidos, especialmente sobre como é afetado o dia a dia da comunidade que passou a dispor de energia elétrica dento de suas residências. $\mathrm{O}$ principal problema identificado nos projetos pesquisados foi a dificuldade de manutenção destes após suas conclusões. Alguns projetos anteriores foram abandonados pela dificuldade financeira de reposição de peças, o que não representava cerca de $8 \%$ do custo total de 
implantação. Outros projetos enfrentaram problemas de gestão por parte da comunidade ou empresa responsável por operação e reparos.

Os projetos de geração de energia partir da fonte solar e biomassa se mostraram satisfatórios e viáveis para a implantação em comunidades isoladas, pois contribuem para a promoção do desenvolvimento sustentável da comunidade permitindo à população o acesso a melhores condições de qualidade de vida. No entanto, para que o projeto se torne eficaz, é necessário um estudo sobre as características do local a ser escolhido para sediar o referido projeto. As características sociais da comunidade influenciam na eficiência do processo, pois cada comunidade aplica um modelo de gestão para o uso da eletricidade de um modo único, utilizando para fins comercias, domésticos ou de entretenimento, atribuído a importância de cada um deles de acordo com o seu modo de vida. As características físicas do local influenciam na capacidade de instalação do sistema, e na ocorrência de interrupções para o fornecimento de energia, pois a quantidade de insumos disposto na região é o fator determinante. 


\section{REFERÊNCIAS}

ALVES, E. F. Qualidade de vida: considerações sobre os indicadores e instrumentos de medida. Revista brasileira de qualidade de vida. Ponta Grossa - PR. v. 03, n. 01, jan./jun, 2011.

ANEEL - Agência Nacional de Energia Elétrica. Atlas da Energia Elétrica do Brasil. Brasília, 2015.

BIRNFELD, A. Estudo sobre as opções tecnológicas em energia renovável para aplicação na região oeste de Santa Catarina. Universidade do Oeste de Santa Catarina, Santa Catarina, 2014.

BORGES, F. Q.; ZOUAIN, D. M. A matriz elétrica e seu posicionamento no desenvolvimento sustentável no estado do Pará. Revista Planejamento e Políticas Públicas, Brasília: IPEA, 35, 187-221, 2010.

BRAGA, R.P. Energia solar fotovoltaica: fundamentos e aplicações. Universidade Federal do Rio de Janeiro/ Escola Politécnica, Rio de Janeiro, 2010.

BRONZATTI, F. L.; NETO, A. I. Matrizes energéticas no Brasil: Cenário 2010-2030. In: Encontro Nacional de Engenharia de Produção, 28., Rio de Janeiro, RJ. Anais... Rio de Janeiro: ENEP, 2008.

CARDOSO, B. M. Uso da biomassa como alternativa energética. Universidade Federal do Rio de Janeiro/ Escola Politécnica, Rio de Janeiro: UFRJ, 2012.

CASTILHO, A. P.; BORGES, N. R. M.; PEREIRA, V. T. Manual de metodologia científica do ILES Itumbiara. Itumbiara/ GO: ILES/ULBRA ITUMBIARA, 2014.

CORTEZ, L. A. B.; LORA, E. E. S.; GÓMEZ, E. O. Biomassa para Energia. Campinas: Editora da Unicamp, 2008.

CODES, A. L. M. de. A trajetória do pensamento científico sobre pobreza: em direção a uma visão complexa, p. 1-33, $2008 . \quad$ Disponível em: http://www.ipea.gov.br/portal/index.php?option=com_content $\&$ view=article $\& i d=488$.

CRESPO, A. P. A.; GUROVITZ, E. A pobreza como um fenômeno multidimensional. RAE electron. vol. 1 no. 2 dez, 2002.

DAGNINO, R.; CAVALCANTI, P. A.; COSTA, G. Gestão estratégica pública. São Paulo: Fundação Perseu Abramo, 2016.

DAY, H.; JANKEY, S.G. Lessons from the literature: toward a holistic model of quality of life. In: RENWICK, R.; BROWN, I.; NAGLER, M. (Eds.). Quality of life in health promotion and rehabilitation: conceptualapproaches, issues and applications. Thousand Oaks: Sage, 1996.

FAPESP Um futuro com energia sustentável: iluminando o caminho / Fundação de Amparo à Pesquisa do Estado de São Paulo. São Paulo: Academia Brasileira de Ciências, 2010. Disponível em:〈http://www.fapesp.br/publicacoes/energia.pdf >. Acesso em 25/12/2019.

FREITAS, G. M. Biomassa, uma fonte de energia. Rio de Janeiro: UFRJ/ Escola Politécnica, 2016.

GOLDEMBERG, J.; MOREIRA, J. R. (2005) Política energética no Brasil. São Paulo: Instituto de Estudos Avançados (IEA)/Universidade de São Paulo (USP), p. 215-228.

HENDERSON, H. Indicadores de qualidade de vida de Calvert-Henderson: uma nova ferramenta para avaliar tendências nacionais. Bethseda: Calvert Group Ltd., 2000.

IBGE. Instituto Brasileiro de Geografia e Estatística. Estatística. Condições de vida, desigualdade e pobreza. Rio de Janeiro: IBGE, 2020. Disponível em: https://www.ibge.gov.br/estatisticas/multidominio/condicoes-de-vida-desigualdade-epobreza.html. Acesso: 02/09/2020. 
IBGE - Instituto Brasileiro de Geografia e Estatística. Cidades. Pará. Breves: IBGE, 2017. Disponível em: <http://cidades.ibge.gov.br/xtras/perfil.php?codmun=150180>. Acesso: 27/12/2020.

IBGE - Instituto Brasileiro de Geografia e Estatística. Estimativas. Pará. Breves: IBGE, 2020. Disponível em: https://www.ibge.gov.br/estatisticas/sociais/populacao/9103-estimativas-depopulacao.html?=\&t=o-que-e. Acesso: 03/09/2020.

MAFRA, F.; SILVA, J. A. Planejamento e gestão do território. Porto: Sociedade portuguesa de inovação, 2004.

MICHALOS, A.C.; ZUMBO, B.D.; HUBLEY, A. Health and the quality of life: social indicators research. Social Indicators Research, Prince George, v.51, n.3, p.245-86, 2000.

MME - Ministério de Minas e Energia. Balanço Energético Nacional - BEN. Brasília: BEN, 2016.

MME - Ministério de Minas e Energia. Matriz Energética Nacional 2030 / Ministério de Minas Energia; colaboração Empresa de Pesquisa Energética. Brasília: EPE, 2007.

MME - Ministério de Minas e Energia. Programa de Incentivo às Fontes Alternativas de Energia Elétrica. Brasília: PROINFA, 2004 Disponível em:<http://www.mme.gov.br/programas/proinfa/>. Acesso em: 25/11/2020.

NAHAS, M. V. Atividade física, saúde e qualidade de vida: conceitos e sugestões para um estilo de vida ativo. Londrina: Midiograf, 2003.

ONU. Convenção Quadro sobre Mudança de Clima. Conferência das Partes. Adoção do Acordo de Paris, 2015. Disponível em <https://nacoesunidas.org/wpcontent/uploads/2016/04/Acordo-de-Paris.pdf >. Acesso em: 24/11/2019.

PADILHA, J. L.; RENDEIRO, G.; BRASIL, A. C. M.; SANTOS, R. E. de J.; PINHEIRO, G. Potencial de geração de energia elétrica no Estado do Pará: utilizando a biomassa do setor madeireiro. Revista Biomassa e Energia, 2(4), 267-284, 2005.

PEREIRA, E. F.; TEIXEIRA, C. S.; SANTOS, A. dos. Qualidade de vida: abordagens, conceitos e avaliação. Rev. bras. Educ. Fís. Esporte. São Paulo, v.26, n.2, p.241-50, abr./jun, 2012.

PINHEIRO, G.; RENDEIRO, G. Potencial de geração de energia utilizando biomassa de resíduos no Estado do Pará. Belém, Pará: UFPA, 2008.

REIS, L. B.; FADIGAS, E. A. F. A.; CARVALHO, C. E. Energia, recursos naturais e a prática do desenvolvimento sustentável. Coleção Ambiental. Barueri, SP: Manole, 2012.

RENWICK, R.; BROWN, I. The center for health promotion's conceptual approach to quality of fi fe. In: RENWICK, R.; BROWN, I.; NAGLER, M. (Eds.). Quality of life in health promotion and rehabilitation: conceptualapproaches, issues and applications. Thousand Oaks: Sage, 1996.

RIBEIRO, B. L. C; SILVA, D. P. Desenvolvimento sustentável e o uso das energias renováveis no Brasil. In: Simpósio de Engenharia de Produção, 6., 2014, São Cristovão, SE. Anais... São Cristóvão, SE: Universidade Federal de Sergipe, 2014.

SAYÃO, A.; MELLO, F. M. O grande papel do potencial hidrelétrico brasileiro: Especialistas apontam como o melhor plano de suprimento futuro de energia para o Brasil pode ser planejado e executado. Rio de Janeiro: Academia Nacional de Engenharia, 2015.

SEN, A. Desenvolvimento como Liberdade. São Paulo: Companhia das Letras, 2000.

SILVA, M. V. M. A dinâmica excludente do sistema elétrico paraense. Escola Politécnica (EP), Faculdade de Economia, Administração e Contabilidade (FEA), Instituto de Eletrotécnica e Energia (IEE), Instituto de Física (IF), São Paulo: USP (Tese Doutorado), 2005.

SILVA, J. J.; BRUNO, M. A. P.; SILVA, D. B. do N. Pobreza multidimensional no Brasil: uma análise do período 2004-2015. Brazil. J. Polit. Econ. vol.40 no.1 São Paulo Jan./Mar. 2020. 
SCHMIDT, S.; POWER, M.; BULLINGER, M.; NOSIKOV, A. The conceptual relationship between health indicators and quality of life: results from the cross-cultural analysis of the EUROHIS fi eld study. Clinical Psychology \& Psychotherapy, Hoboken, v.2, n.1, p.28-49, 2005.

SCHULTZ, G. Introdução à gestão de organizações. Porto Alegre: books.google.com, 2016. SOARES, S. S. D. Metodologias para estabelecer a linha de pobreza: objetivas, subjetivas, relativas, multidimensionais', p. 53, 2009. Disponível em : http://www.ipea.gov.br/portal/index.php?option=com_content\&view=article\&id=4933.

SOARES, T. S.; CARNEIRO, A. C.O.; GONÇALVES, E. O.; LELLES, J. G. Uso da biomassa florestal na geração de energia. Revista Científica Eletrônica de Engenharia Florestal. Garça, Ano IV, n. 08, agosto, 2006.

TIRADENTES, A. A. R. Uso da energia solar para geração de eletricidade e para aquecimento de água., Minas Gerais: UFL, 2007.

UNICA. Etanol e Bioeletricidade: A cana-de-açúcar no futuro da matriz energética. Projeto AGORA - Agroenergia e Meio Ambiente, 2010.

UNCTAD - Conferência das Nações Unidas sobre Comércio e Desenvolvimento. The 2017 Least developed countries report: access to transformational energy. Genebra: UNCTAD, 2017.

WCED - World Commissionon Environment Development. Uma visão geral. Oxford: Universidade de Oxford, 1991.

WHOQOL Group. The development of the World Health Organization quality of life assessment instrument (the WHOQOL). In: ORLEY, J.; KUYKEN, W. (Eds.). Quality of life assessment: international perspectives. Heidelberg: Springer, 1994.

WWF - World Wide Fund for Nature. Além das Grandes Hidrelétricas, Política para fontes renováveis de energia elétrica no Brasil. Brasília: WWF, 2012. 